\title{
DEFEITOS SUPERFICIAIS EM 2H-WS 2 OBSERVADOS POR MICROSCOPIA DE TUNELAMENTO
}

F. Wypych

Universidade Federal do Paraná - CP 19081 -81531-990 - Curitiba - PR

Th. Weber e R. Prins

ETH - Eidgenössische Technische Hochschule - Laboratorium für Technische Chemie - CH 8092 - Zürich - Switzerland

Recebido em 28/10/96; aceito em 23/7/97

\begin{abstract}
SURFACE DEFECTS ON 2H-WS 2 DETECTED BY SCANNING TUNNELLING MICROSCOPY. Scanning tunnelling microscopy (STM) was used to characterise the basal surface of fresh cleaved crystals of $2 \mathrm{H}-\mathrm{WS}_{2}$. Although no impurity or stacking faults could be detected by $\mathrm{X}$-ray diffraction, STM images obtained with negative bias voltage showed two kinds of defects. These defects were attributed to an iodine derivative used as transport agent. In a flat surface free of defects, an image with atomic resolution was achieved with sulphur distances and angles as expected for hexagonal symmetry of $2 \mathrm{H}-\mathrm{WS}_{2}$.
\end{abstract}

Keywords: scanning tunnelling microscopy; tungsten disulphide; catalysis.

\section{INTRODUÇÃO}

Dicalcogenetos de metais de transição (DCMT) dos grupos IV a VIB pertencem a uma classe de substâncias conhecidas como compostos lamelares bidimensionais. Uma característica fundamental que os diferencia dos materiais que cristalizam em estruturas tridimensionais, se baseia na construção dos cristais. Essa construção se dá através do empilhamento de unidades bidimensionais chamadas lamelas (de três átomos de espessura) deixando entre elas um espaço vazio conhecido como lacuna de van der Waals. Essa lacuna, constituída de sítios vacantes de geometria conhecida pode ser ocupada por cátions ou moléculas neutras, solvatadas ou não, através de um processo de intercalação. Os produtos (normalmente não estequiométricos), são conhecidos como compostos de intercalação.

Outra característica bastante singular é que diferentes sequências de empilhamento das lamelas poderão gerar estruturas (politipos ou polimorfos) com propriedades físicas completamente diferentes entre si. Esses compostos são diferenciados entre si através de uma nomenclatura que utiliza um número seguido de uma letra maiúscula. $O$ número informa quantas lamelas são necessárias para formar uma cela unitária na direção [001] do cristal (direção basal) e a letra informa o sistema cristalino a que pertence o cristal.

Como o trabalho descrito abaixo se concentra no estudo de defeitos superficiais de um monocristal do politipo $2 \mathrm{H}$ do dissulfeto de tungstênio, passaremos a seguir à descrição dos diferentes politipos existentes e logo em seguida à estrutura e propriedades do referido politipo.

O dissulfeto de tungstênio ocorre na forma de 4 politipos, reportados na literatura. Um deles, o $2 \mathrm{H}$ (hexagonal) é termodinamicamente estável ${ }^{1,2}$. Os outros 3 politipos que são metaestáveis apresentam-se como: 3R (romboédrico ${ }^{1,2}$ ), o (ortorrômbico) $^{3}$ e $2 \mathrm{M}$ (monoclínico) ${ }^{4}$. É bastante provável que nos politipos ortorrômbico e monoclínico, a fase seja a mesma: monoclínica com duas lamelas por cela unitária, na direção basal.

$\mathrm{O}$ politipo $2 \mathrm{H}$ é um semicondutor, onde os átomos de tungstênio são coordenados a seis átomos de enxofre formando um prisma trigonal regular no qual cada átomo de enxofre está ligado a três átomos de tungstênio sendo os prismas ligados pelos vértices. Na lamela as forças são covalentes, enquanto que as ligações entre as lamelas são fracas do tipo van der Waals, o que propicia as propriedades anisotrópicas do material e facilita a sua clivagem segundo o plano basal (plano " $\mathrm{a} x$ b"), perpendicular à direção [001] do cristal.

A figura 1(a) apresenta a estrutura tridimensional do $2 \mathrm{H}$ $\mathrm{WS}_{2}$ e sua projeção segundo o plano basal (b). As direções cristalográficas [010], [100] e o corte da cela unitária segundo a direção [11-20] são mostradas na figura 1(b) (linha tracejada).

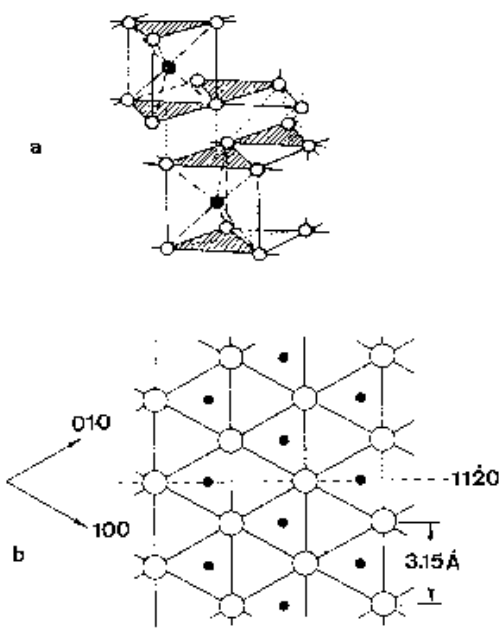

Figura 1. Estrutura tridimensional do $2 \mathrm{H}-W S_{2}$ (a) e sua projeção segundo o plano basal (b). Átomos de tungstênio e enxofre são representados por esferas pretas menores e círculos não preenchidos, respectivamente.

No processo de clivagem a superfície basal consiste de arranjos hexagonais de átomos de enxofre, todos com suas ligações saturadas. Esta característica proporciona uma baixa reatividade do material segundo a direção acima citada, sendo esta considerada inerte.

A importância de conhecer tais superfícies e como elas interagem com agentes externos está diretamente ligada a eficiência de catalisadores heterogêneos, que consistem basicamente de processos superficiais. As superfícies dos dissulfetos de molibdênio e tungstênio tornam-se mais importantes, já que estes materiais são constituintes básicos na formulação dos catalisadores de hidrotratamento ${ }^{5}$.

Estes catalisadores são responsáveis pela diminuição do efeito poluidor dos combustíveis pela retirada seletiva de enxofre 
(hidrodessulfurização - HDS), nitrogênio (hidrodenitrogenação HDN), oxigênio (hidrodeoxigenação - HDO), metais (hidrodemetalização -HDM), etc. Os átomos de nitrogênio, oxigênio e enxofre que devem ser retirados do combustível estão presentes na forma de heteroátomos nas estruturas do petróleo, e os metais presentes na forma de complexos organometálicos, sendo complexados principalmente pelos heteroátomos acima citados.

Nestes materiais, um precursor, (geralmente molibdato ou tungstato de amônio) é impregnado em uma matriz porosa inerte com boas propriedades mecânicas, (geralmente $\gamma-\mathrm{Al}_{2} \mathrm{O}_{3}$ ) coimpregnado com um agente dopante (sal solúvel de $\mathrm{Ni}$ ou Co, Ex.: sulfato) e o conjunto calcinado a uma temperatura entre 350 e $450^{\circ} \mathrm{C}$. Utilizando-se uma mistura de $\mathrm{H}_{2} \mathrm{~S}$ diluído em $\mathrm{H}_{2}$, os materiais são sulfetados "in-situ", produzindo o catalisador comumente utilizado na indústria petroquímica.

Uma pergunta de grande importância que envolve a determinação do sítio ativo neste sistema tem ocupado grande parte dos pesquisadores envolvidos com catálise heterogênea nas últimas décadas. Com a aplicação de técnicas de análise mais sofisticadas ${ }^{6,7}$, uma tendência tem sido projetada para a aceitação de um sítio ativo do tipo Ni-Mo-S ${ }^{7,8}$, onde o níquel ocupa uma posição dos sítios insaturados nas laterais das lamelas. Apesar desta tendência, não existe na literatura especializada um consenso a esse respeito.

Como a superfície basal dos compostos lamelares é considerada inerte, a maioria dos esforços tem sido concentrados no estudo das laterais das lamelas.

Devido a importância tecnológica dos dissulfetos de molibdênio e tungstênio principalmente como catalisadores, lubrificantes sólidos $\left(2 \mathrm{H}-\mathrm{MoS}_{2}\right.$ é o material lamelar com melhores propriedades tribológicas até o momento descrito) e materiais para eletrodos de baterias, alguns estudos de monocristais naturais através de microscopia de tunelamento (STM) têm sido reportados ${ }^{9-12}$. Em alguns casos, defeitos superficiais foram observados em monocristais naturais de $2 \mathrm{H}-\mathrm{MoS}_{2}{ }^{11}$ e cristais de $\mathrm{Ni}_{0,1} \mathrm{Mo}_{0,9} \mathrm{~S}_{2}$ crescidos pelo método de transporte de vapor ${ }^{12}$.

$\mathrm{O}$ objetivo deste estudo consiste em analisar a superfície basal de cristais recentemente clivados de $2 \mathrm{H}-\mathrm{WS}_{2}$, crescidos através do método de transporte de vapor utilizando-se iodo como agente transportante. $\mathrm{O}$ resultados aqui reportados fazem parte de um conjunto de estudos associados a superfícies de sulfetos semicondutores e condutores, que será motivo de publicações posteriores ${ }^{13-15}$.

\section{EXPERIMENTAL}

O material básico neste estudo foi sintetizado como descrito por Lieth e Terhell ${ }^{16}$. O método consiste em selar quantidades estequiométricas de enxofre e tungstênio na forma de pó (grau PA), (cerca de $3 \mathrm{~g}$ ) em uma ampola de quartzo (20 cm de comprimento; $2,5 \mathrm{~cm}$ de diâmetro interno e $0,25 \mathrm{~cm}$ de espessura de parede). Após várias purgas com argônio, seguidas de vácuo, a ampola foi selada sob pressão aproximada de $10^{-5}$ Torr e aquecida por 7 dias a uma temperatura de $950^{\circ} \mathrm{C}$ (a ampola foi aquecida e esfriada a uma velocidade de $100^{\circ} \mathrm{C} / \mathrm{h}$ ). Após o esfriamento da ampola até a temperatura ambiente $\left(23 \pm 1^{\circ} \mathrm{C}\right)$, o material foi retirado, moído e selado novamente na mesma ampola. Como agente transportante adicionou-se à ampola, iodo metálico (purificado por sublimação) na proporção de $1 \mathrm{mg} / \mathrm{cm}^{3}$ do volume da ampola. A ampola foi mergulhada em um Dewar contendo nitrogênio líquido, purgada várias vezes com argônio, e selada sob pressão aproximada de $10^{-5}$ Torr. O material na forma de pó foi deslocado para uma ponta da ampola, a qual foi posicionada em um forno tubular com gradiente de temperatura. A ponta da ampola com o material foi aquecida a $900^{\circ} \mathrm{C}$ enquanto que a outra foi aquecida a $850^{\circ} \mathrm{C}$, utilizando-se o próprio gradiente do forno tubular. Nessas condições, a ampola permaneceu no forno por um período de 15 dias. Esse gradiente faz com que o material possa ser transportado para a ponta mais fria da ampola na forma de aglomerados de cristais. Os aglomerados consistiam de monocristais de $2 \mathrm{H}-\mathrm{WS}_{2}$ de hábito hexagonal, de até $3 \mathrm{~mm}$ de diâmetro. $\mathrm{O}$ material não transportado consistindo de pequenas placas hexagonais após lavagem com acetonitrila, foi analisado por difratometria de raios-X (modo transmissão), utilizando-se um difratômetro STOE operando a $40 \mathrm{KV}$ e $35 \mathrm{~mA}$ $\left(\mathrm{CuK}_{\alpha 1}=1,54056 \AA\right)$. Para este experimento, os cristalitos foram selados em um capilar de Lindemann de $0,3 \mathrm{~mm}$ de diâmetro, o qual foi submetido a movimentos de rotação durante o experimento. Os dados acumulados por 20 minutos e coletados através de um detector sensível a posição foram utilizados para a caracterização do politipo sintetizado.

Para a análise superficial através de microscopia de tunelamento um cristal transportado foi selecionado, (cerca de $2 \mathrm{~mm}$ ), clivado com fita adesiva comum e colado em um porta amostras metálico utilizando-se cola condutora de prata. Como a microscopia de tunelamento exige que o material seja condutor ou semicondutor, e devido a alta anisotropia de condutividade elétrica do $2 \mathrm{H}-\mathrm{WS}_{2}$, não só a base do cristal mas também as laterais foram coladas com cola de prata. Quando este procedimento não é adotado, a geração de imagens é normalmente bastante dificultada.

O equipamento utilizado foi um microscópio de tunelamento modelo Nanoscope II da Digital Instruments Inc., Santa Bárbara. As medidas foram realizadas ao ar, temperatura ambiente $\left(23 \pm 1^{\circ} \mathrm{C}\right)$, modo de corrente constante ${ }^{17}$ e utilizando-se pontas de $\mathrm{Pt}_{0,8} \mathrm{Ir}_{0,2}$ de $0,25 \mathrm{~mm}$ de diâmetro disponíveis comercialmente, ou fabricadas no laboratório. A qualidade das pontas (que teoricamente deveria consistir de um único átomo isolado) foi testada em um monocristal de grafite pirolítico altamente orientado (HOPG), sendo consideradas boas aquelas pontas que produziam imagens com resolução atômica.

Nas medidas realizadas através do modo de corrente constante, a ponta se movimenta para cima e para baixo (no modo varredura) de forma a manter a corrente de tunelamento constante ${ }^{17}$. Em todos os experimentos foram utilizadas tensões negativas, o que representa o fluxo eletrônico da amostra para a ponta metálica. As imagens geradas pelo microscópio de tunelamento consistem em imagens das densidades eletrônicas superficiais associadas a níveis de energia nas proximidades do nível de Fermi, em função da distância entre a superfície e a ponta metálica. Desta forma, nos sulfetos lamelares a imagem mostra normalmente os átomos de enxofre superficiais que representam a rede real do plano cristalográfico analisado ${ }^{18}$. Esse é um caso especial, porque a geometria dos átomos metálicos é exatamente a mesma dos átomos de enxofre superficiais e desta forma as distâncias interatômicas determinadas correspondem aos parâmetros de rede cristalográficos (Figura 1(b)). No caso estudado, a imagem é constituída de pontos claros correspondentes aos átomos de enxofre superficiais do plano basal, mostrados como elevações na imagem topográfica, separados por regiões escuras, mostradas como depressões na imagem topográfica.

\section{RESULTADOS E DISCUSSÕES}

A figura 2 apresenta um difratograma de raios-X do material não transportado, após lavagem do excesso de iodo com acetonitrila. Dados foram acumulados por 20 minutos, após o material ter sido selado em um capilar de Lindemann de 0,3 $\mathrm{mm}$ de diâmetro. Utilizando esse procedimento se evita a intensificação das reflexões basais pela orientação preferencial dos cristalitos em um porta amostras plano.

Todas reflexões observadas no difratograma de raios-X (Figura 2) foram indexadas através do politipo $2 \mathrm{H}$, não sendo observada nenhuma reflexão relativa a alguma eventual impureza.

Os parâmetros foram refinados pelo programa comercial fornecido pelo próprio fabricante do equipamento, sendo $\mathrm{a}=\mathrm{b}=$ $3,15 \AA$ e $c=12,35 \AA$ portanto, idênticos aos valores citados na literatura $^{1,2}$. 


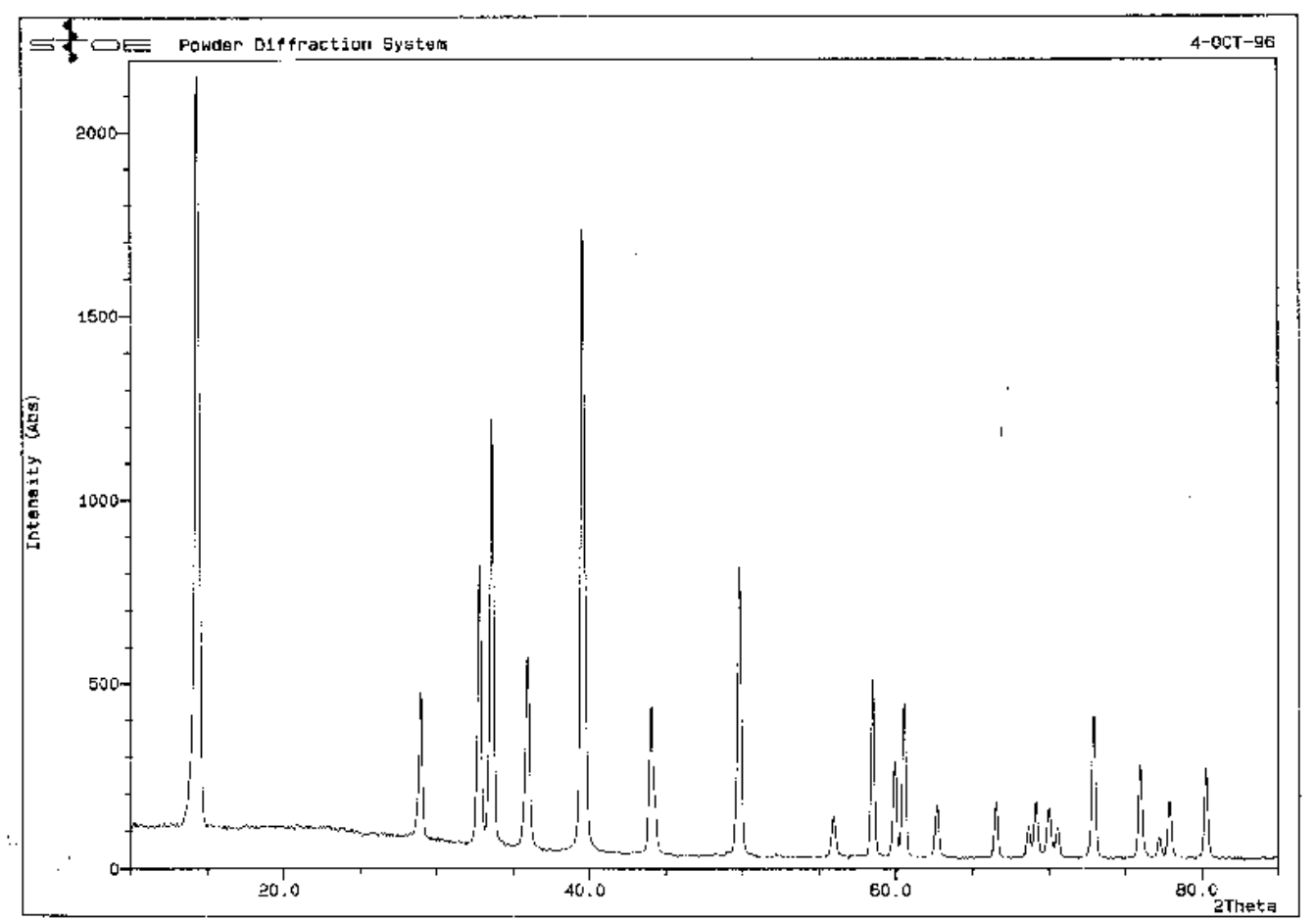

Figura 2. Difratograma de raios-X do material não transportado, após lavagem do excesso de iodo com acetonitrila. Dados acumulado por 20 minutos.

A escolha da fase $2 \mathrm{H}$ baseia-se principalmente no fato desta ser o politipo termodinamicamente estável e pela sua importância como catalisador de hidrotratamento e lubrificante sólido. Apesar desta escolha, a determinação da estrutura do politipo não é tão importante, já que a diferença entre os dois casos (2H e 3R) consiste basicamente no empilhamento diferenciado das lamelas que são praticamente idênticas.

A figura 3 mostra uma imagem do plano basal de um monocristal de $2 \mathrm{H}-\mathrm{WS}_{2}$, obtida via STM. A figura é apresentada em tons que variam de branco a preto, que representam densidades eletrônicas altas e baixas respectivamente. No modo topográfico, as reflexões claras se apresentam como elevações e as imagens negras como depressões. A figura 3 representa o dado gerado sem manipulação ou utilização de filtros e apresenta manchas brancas de densidade eletrônica e alguns traços que lembram a resolução atômica da superfície basal do $2 \mathrm{H}-\mathrm{WS}_{2}$. Ao contrário do que se esperava, a superfície encontra-se contaminada com pequenas elevações de material estranho (defeitos). Os dois defeitos indicados por D1 e D2 obervados na figura 3 são de $25 \AA$ de diâmetro por $14 \AA$ de altura e $16 \times 10 \AA$, respectivamente.

A composição do material estranho não foi determinada, mas provavelmente consiste de um derivado de iodo, utilizado como agente transportante na forma de $\mathrm{WI}_{4}$. As imagens se repetem após suscessivas clivagens, mostrando que o material estranho não cresce preferencialmente na superfície dos cristais e sim distribuído no interior dos cristais. Em alguns casos aglomerados são observados, em outros casos, pequenas ilhas isoladas circundadas por grandes regiões bastante limpas. $\mathrm{Ne}-$ nhuma reflexão estranha foi observada no difratograma de raios-X, que pudesse ser atribuída a uma eventual impureza. Alterações dos parâmetros de rede também não foram observadas. Esta constatação leva a crer que os defeitos de dimensões manoscópicas são em pequeno número, o que não impede a boa cristalização do material. Provavelmente, quando um grande depósito de material estranho ocorre, o cristal experimenta uma falha de crescimento e talvez esta explique o fato do cristal crescer na forma de um mosaico. Os cristais, evidentemente sofrem processos de clivagem preferencial nessas direções, o

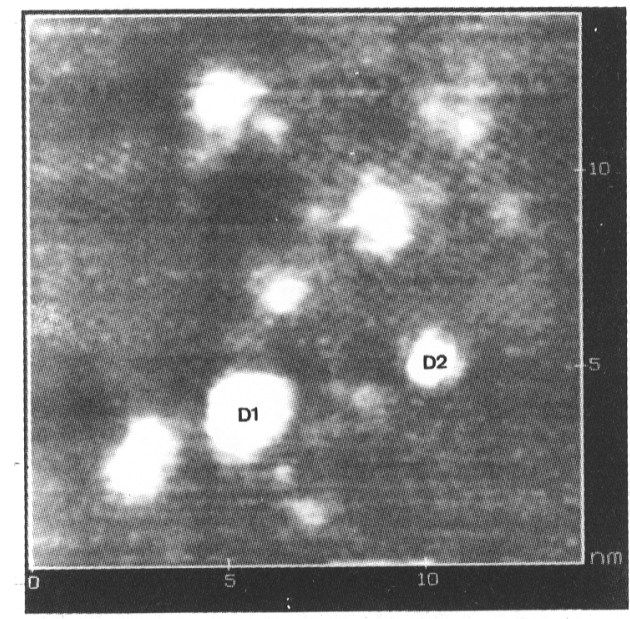

Figura 3. Imagem da superfície basal do monocristal de $2 \mathrm{H}-\mathrm{WS}_{2}$ (área de $150 \times 150 \AA)$ obtida via STM. Condições de medida: tensão de $-950 \mathrm{mV}$ e corrente de tunelamento constante de $3 \mathrm{nA}$. Os defeitos são indicados por D1 e D2.

que expõe essas elevações a observação. Isso não impede, entretanto, que regiões bastante limpas da mesma superfície sejam observadas. Observações suscessivas após várias clivagens mostram que a quantidade destas elevações é relativamente pequena, porém difíceis de serem quantificadas.

A figura 4 apresenta uma resolução atômica da superfície basal de um monocristal do $2 \mathrm{H}-\mathrm{WS}_{2}$, (sem uso de filtros). Nesta figura observa-se um defeito (indicado por D) e ao fundo uma superfície com resolução atômica.

Ao lado esquerdo do defeito encontra-se uma pequena depressão (região escura) provocada provavelmente pelo brusco movimento da ponta, durante o movimento de varredura.

A figura 5 (a) apresenta uma imagem obtida via STM com resolução atômica numa área de 40 x $40 \AA$ onde um outro tipo de defeito se apresenta. Esta imagem foi filtrada para retirada 


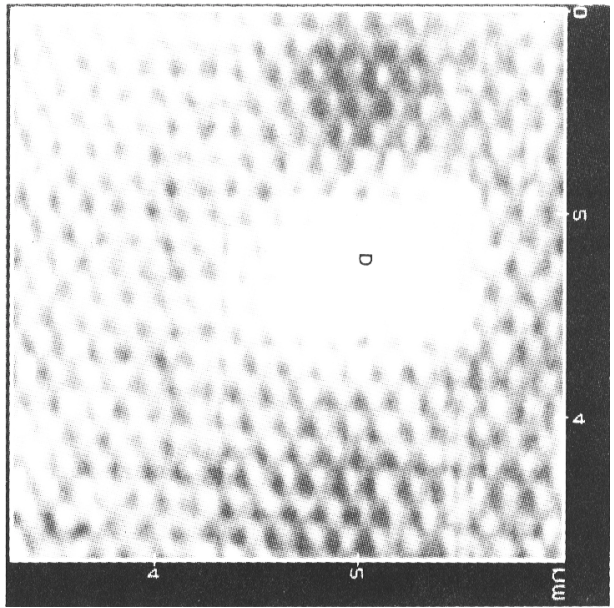

Figura 4. Imagem da superfície basal (área de $50 x \quad 50 \AA$ ) do monocristal de $2 \mathrm{H}-\mathrm{WS}_{2}$ obtida via STM. Condições da medida: tensão de $-1038,8 \mathrm{mV}$ e corrente de $3 \mathrm{nA}$. $O$ defeito é indicado por $D$.
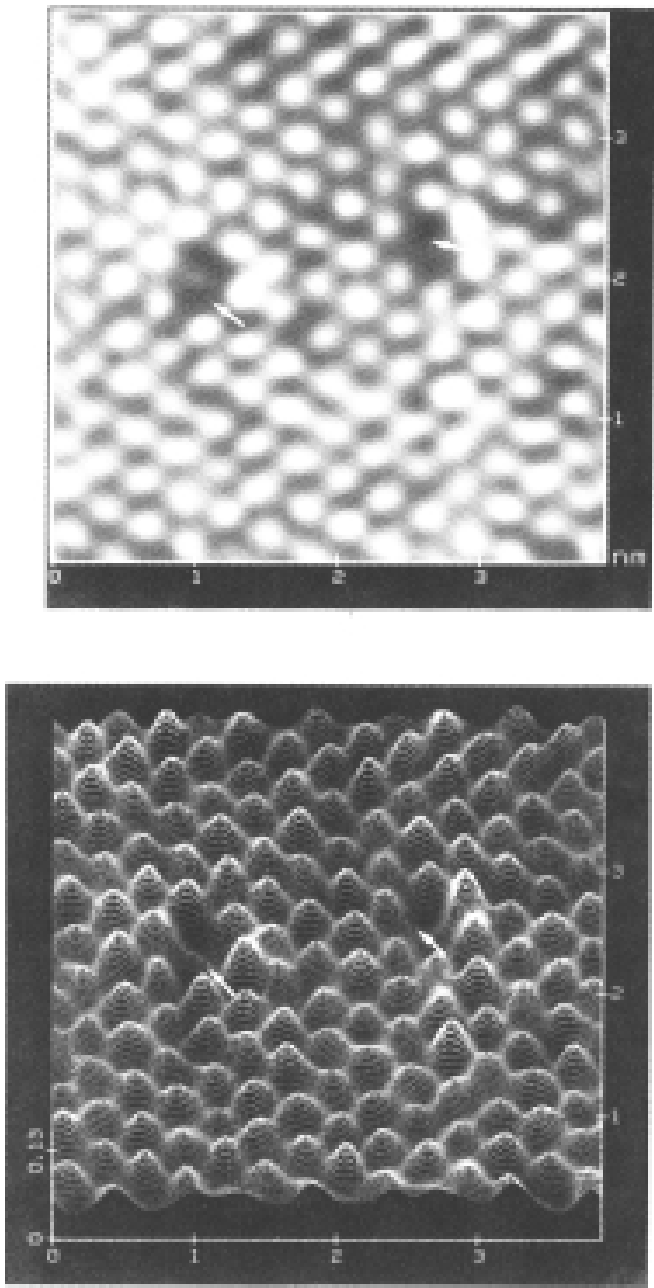

Figura 5. Imagem da superfície basal (área de $40 \times 40 \AA$ ) do monocristal de $2 \mathrm{H}-\mathrm{WS}_{2}$ obtida via $\operatorname{STM}($ a). Condições da medida: tensão de $-1062 \mathrm{mV}$ e corrente de 3,3 nA. Projeção topográfica com uma rotação de $30^{\circ}$ em relação ao plano da imagem (b). Defeitos indicados pelas setas.

de frequências relativas a vibrações do equipamento, e também ruídos de fundo. Nessa imagem são observados os átomos de enxofre distribuídos periodicamente (reflexões claras), formando uma estrutura hexagonal na rede real.

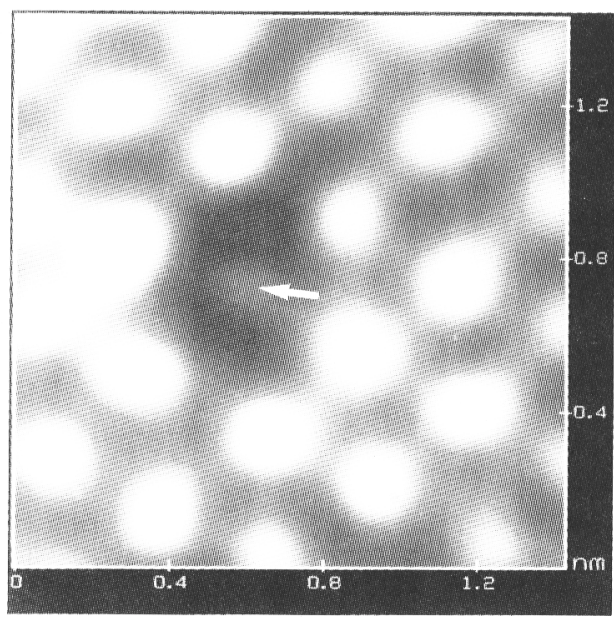

(A)

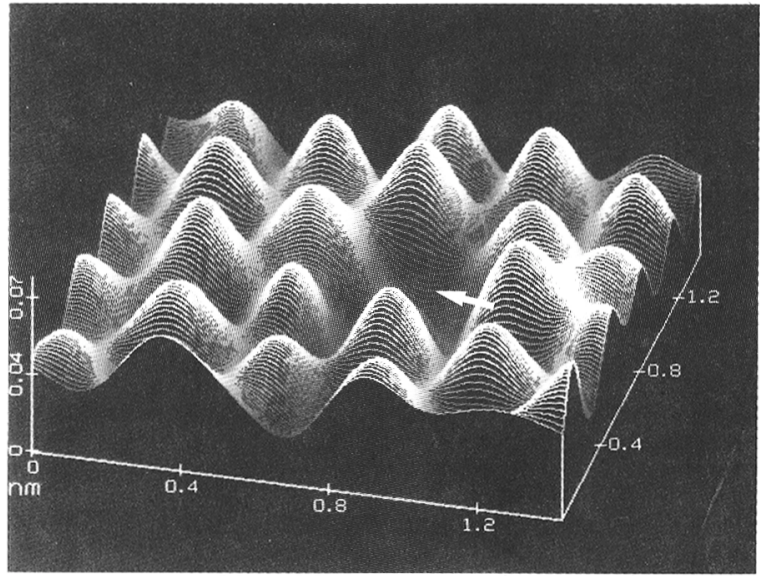

(B)

Figura 6. Imagem da superfície basal (área de $14 \times 14 \breve{\text { ) }}$ do monocristal de $2 \mathrm{H}-\mathrm{WS}_{2}$ obtida via STM (a). Condições da medida: tensão de $-1062 \mathrm{mV}$ e corrente de 3,3 nA. Projeção topográfica com uma rotação de $60^{\circ}$ em relação ao plano da imagem (b). Defeito indicado por uma seta.

Existem duas hipóteses para a explicação do defeito apresentado na figura 5(a). A primeira consiste na existência de uma vacância de enxofre, que se apresenta como uma região escura na posição onde deveria estar presente uma reflexão clara do átomo de enxofre. A segunda hipótese consiste no crescimento de um material não condutor exatamente em cima do átomo de enxofre, mascarando a densidade eletrônica do mesmo.

Como cada enxofre está ligado a três átomos de tungstênio através de ligações bastante fortes, e que vacâncias de enxofre somente são observadas após um processo de redução com hidrogênio a temperaturas relativamente altas, a segunda hipótese parece ser a mais provável.

A figura 5(b) apresenta uma imagem topográfica com uma rotação de $30^{\circ}$ em relação ao plano da imagem da figura 5(a). Nesta figura observam-se os dois defeitos, próximos de reflexões de densidade eletrônica maior, provavelmente pela influência da molécula estranha nas imediações ou vacância do enxofre.

A figura 6(a) apresenta uma expansão da figura 5(a), onde somente um defeito (indicado pela seta) é focalizado (imagem filtrada). A figura 6(b) apresenta uma imagem topográfica da figura 6(a), com um ângulo de rotação de $60^{\circ}$ em relação ao plano da imagem, para melhor visualização do defeito, que se encontra exatamente na posição cristalográfica do enxofre no meio do hexágono. 
A figura 7(a) apresenta uma imagem obtida via STM de uma área de 120 x $120 \AA$ onde se observa a resolução atômica (imagem sem filtros), da superfície basal do $2 \mathrm{H}-\mathrm{WS}_{2}$.

Esta figura foi obtida nas mesmas condições da figura 6 . A partir desta figura após um processo de filtragem, as distâncias interatômicas nas direções [010] e [100] foram determinadas como sendo 3,2 $\pm 0,1 \AA$. Como a geometria dos átomos metálicos é exatamente a mesma dos átomos de enxofre superficiais, as distâncias interatômicas aqui determinadas correspondem aos parâmetros de rede da estrutura no plano basal, que são bastante próximas dos valores determinados por difratometria de raios-X ou seja, $a=b=3,15 \AA$.

O ângulo na cela unitária foi determinado como sendo 120 $\pm 0,5^{\circ}$, o que corresponde ao valor esperado de $120^{\circ}$ para uma estrutura hexagonal. A figura 7(b) mostra um diagrama da figura 7(a) após um processo de filtragem com transformada de Fourier bidimensional. Nessa imagem observa-se um hexágono com somente uma distância interplanar e um ângulo de $120^{\circ}$, o que confirma a estrutura hexagonal da superfície analisada.

A figura 8 (a) apresenta uma expansão da figura 7 numa área de 9 × $9 \AA$, onde são observadas duas celas unitárias formando um hexágono regular. As direções cristalográficas da

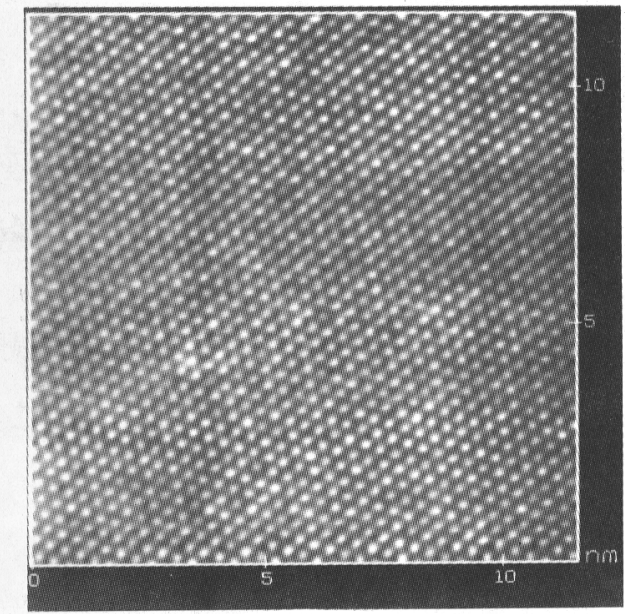

(A)

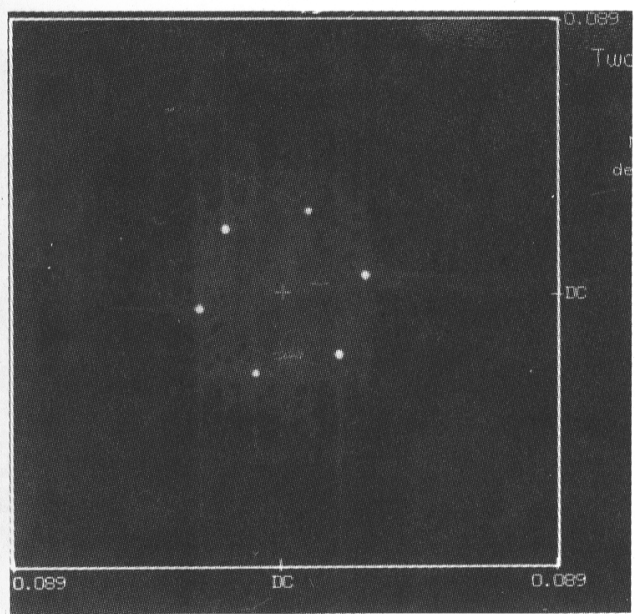

(B)

Figura 7. Imagem da superfície basal (área de $120 \times 120 \AA$ ) do monocristal de $2 \mathrm{H}-\mathrm{WS}_{2}$ obtida via STM (a). Condições da medida: tensão de $-1062 \mathrm{mV}$ e corrente de 3,3 nA. Correspondente diagrama após um processo de filtragem com transformada de Fourier bidimensional (b). cela unitária inferior são indicados com [100] e [010]. A direção [001] se encontra perpendicular às duas outras direções. A figura 8(b) mostra novamente uma projeção topográfica da figura 7 (a), com uma rotação de $30^{\circ}$ em relação ao plano da imagem.

Os defeitos aqui observados são de importância fundamental para a catálise heterogênea, que utiliza sulfetos lamelares já que os planos basais dos cristalitos são normalmente considerados inertes.

Essa observação demonstra que apesar dos sulfetos analisados terem sido sintetizados a uma temperatura de $900^{\circ} \mathrm{C}$, defeitos nos planos basais estão presentes. Quando temperaturas menores são utilizadas, (caso dos catalisadores de hidrotratamento) os cristalitos dos dissulfetos são extremamente pequenos, basicamente amorfos e muito mais suscetíveis a defeitos do que os cristais aqui reportados. $\mathrm{O}$ método de preparação pode ser determinante para gerar materiais em que o plano basal passa a desempenhar um papel importante.

Dependendo da relação área do plano basal/área do plano lateral e do número de defeitos observados, os defeitos basais podem ser muito importantes ou até determinantes na atividade catalítica de um catalisador lamelar.

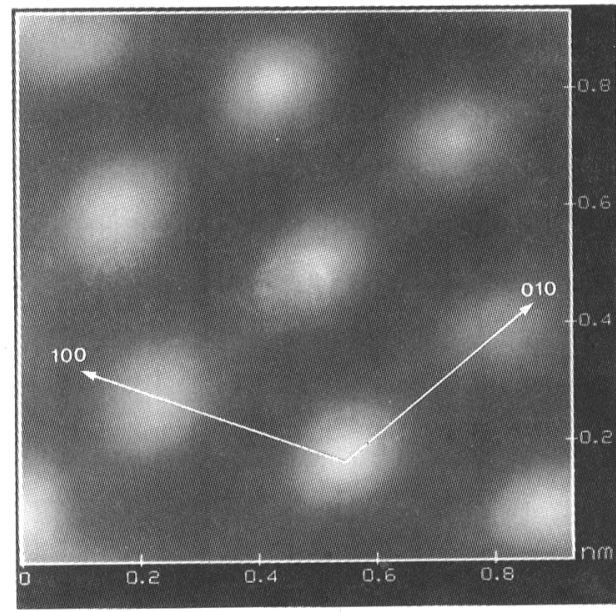

(A)

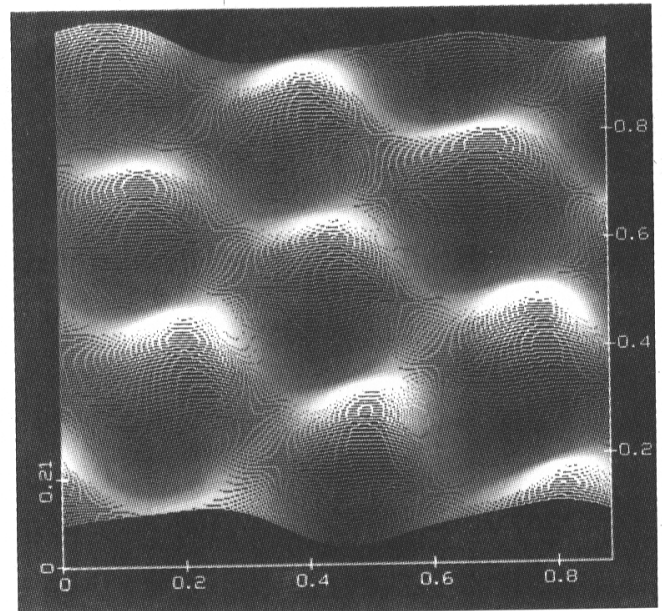

(B)

Figura 8. Imagem da superfície basal (área de $9 \times 9 \AA$ ) do monocristal de $2 \mathrm{H}-\mathrm{WS}_{2}$ obtida via STM (a). Condições da medida: tensão de - $1062 \mathrm{mV}$ e corrente de 3,3 nA. Projeção topográfica com uma rotação de $30^{\circ}$ em relação ao plano da imagem $(b)$. 


\section{CONCLUSÕES}

Utilizando-se o método de transporte de vapor (iodo como agente transportante), produz-se um material que analisado por difratometria de raios- $X$, apresenta-se bastante cristalino e aparentemente livre de qualquer outro material estranho. Através de uma análise precisa do material observando-se superfícies basais clivadas, através de microscopia de tunelamento constatou-se que: 1 - O material está contaminado por um material estranho, provavelmente um derivado do iodo não condutor, alojado no interior do cristal provocando falhas de crescimento.

2 - O material de contaminação está presente na forma de pequenos cristalitos de alguns ângstrons de altura e diâmetro, alojados no interior do cristal.

3 - Outro tipo de defeito observado consiste provavelmente de uma molécula isolada do material ligada a um átomo enxofre da superfície ou uma vacância de enxofre.

\section{AGRADECIMENTOS}

- Ao Departamento de Química da UFPR pela concessão do afastamento durante a realização desse trabalho.

- Ao Prof. Dr. Roel Prins pelo convite e apoio financeiro.

\section{REFERÊRENCIA}

1. Schutte, W. J.; De Boer, J. L.; Jellinek, F.; J. Solid Stat. Chem. 1987, 70, 207.

2. Wildervanck, J. C.; Jellinek, F.; Z. Anorg. Allg. Chem. 1964, 328, 309.

3. Schöllhorn, R.; Bethel, U.; Paulus, W.; Rev. Chim. Miner. 1984, 21, 545.
4. Wypych, F.; Sollmann, K.; Schöllhorn, R.; Mat. Res. Bull. 1992, 27, 545.

5. Prins, R.; de Beer, V. H. J.; Somorjai, G. A.; Cat. Rev.Sci. Eng. 1989, 31, 1.

6. Prins, R.; Koningsberger, D. C.; in Prins, R.; Koningsberger, D. C.; (Ed.) em X-ray absorption, John Wiley e Sons, New York 1988; p. 321.

7. Topsoe, H.; Clausen, B. S.; Massoth, F. E.; em Hydrotreating Catalysis - Science and Technology, Springer Verlag, Berlin, 1996; p. 31.

8. Knözinger, H.; Proc. $9^{\text {th }}$ Int. Congr. Catal. (Calgary). Philips, M. J.; Ternan, M. (Ed.), vol 5, 1988.

9. Weimer, M.; Kramar, J.; Bai, C.; Baldeschwieler, J. D.; Phys. Rew. B 1988, 37, 4292.

10. Sarid, D.; Henson, T. D.; Armstrong, N. R.; Bell, L. S.; Appl. Phys. Lett. 1988, 52, 2252.

11. Hosoki, S.; Hosaka, S.; Hasegawa, T.; Appl. Surf. Science 1992, 60/61, 643.

12. Lieber, C. M.; Kim, Y.; Thin Solid Film. 1991, 206, 355.

13. Wypych, F.; Weber, Th.; Prins, R.; Surf. Sci. Let. 1997, 380,474

14. Wypych, F.; Weber, Th.; Crosender, C.; Prins, R.; a ser submetido para J. Solid State Chem., 1997.

15. Wypych, F.; Weber, Th.; Prins, R.; Chem. Mat., 1997, no prelo.

16. Lieth, R. M. A.; Terhell, J. C. J. M.; in Lieth, R. M. A.; (Ed.) em Preparation and crystal growth of materials with layered structure, vol 1, Boston, 1977, p. 212.

17. Hansma, P. K.; Tersoff, J.; J. Appl. Phys. 1987, 61, R1.

18. Magonov, S. N.; Whangbo, M-H.; Adv. Mat. 1994, 6,355 . 